\title{
Effects of ingredients and processing conditions on the quality frozen dough bread made from diferent wheat flour
}

\author{
Ruska Laslo, Timar Adrian
}

University of Oradea, romimplement@yahoo.com

\begin{abstract}
Summary
A laboratory scale no-time frozen dough procedure that approximates Romanian commercial practice has been developed and used to study the effects of ingredients and processing conditions on the bread quality of a straight grade wheat flour during prolonged storage (2 days to 26 weeks). All treatments (baking absorption level, mixing energy input, mixer type, fermentation and intermediate proof times, removal of oxidant and/or dough strengthening conditioners and partial freeze-thaw cycles) had significant effects $(P<0.05)$ upon bread quality (loaf volume and/or bread score). In general, these effects were more pronounced with extended frozen storage time. High baking absorption, undermixing, bulk fermentation (> 1 h) and removal of oxidant and/or surfactants had the most dramatic effects. Addition of a very strong flour at $30 \%$ to strengthen the wheat flour had no significant effect $(P>0.05)$ upon bread quality under optimum conditions.
\end{abstract}

Keywords: wheat flour, baking, processing conditions, flour storage.

\section{INTRODUCTION}

Several factors have been shown to play an important role in the quality of bread produced from frozen dough during prolonged storage. The effect of freezing on yeast properties has been the area of most concern. Yeast type and properties also play an important role in determining yeast viability and product quality. In most commercial frozen dough production facilities in Romania, higher yeast levels, no-time dough processing procedures, low processing temperatures and the use of blast freezers are used to minimize these effects.

The other major factor that may play an important role in frozen dough product quality is the influence of storage time and conditions on gluten structure. The structure of the gluten protein matrix appears to be disrupted during extended storage or repeated freeze-thaw cycles (Berglund et al, 1991), resulting in a weakening of dough strength properties, loss of gas retention properties and deterioration of product quality (Inoue et al, 1994). The extent of these adverse effects may be reduced by using very strong flours by the addition of gluten or by addition of dough strengthening agents such as sodium stearoyl lactylate (SSL) or diacetyl tartaric acid esters (DATEM) of mono- and diglycerides (Inoue et al, 1995).

\section{MATERIALS AND METHODS}

\section{Wheat and flour properties}

The wheat was milled to straight grade flour on a small commercial mill at the Bicaci mill, Bihor county. The flour had a protein content of $12.7 \%$ (Nx5.7), ash content of $0.55 \%$, starch damage of 28 Farrand units (8.6 AACC units), Farinograph absorption of $64.0 \%$, Farinograph dough development time of 6.5 min and Farinograph stability of $11.5 \mathrm{~min}$. The methods used to obtain these results are described in a previous publication and references cited therein (Preston et al, 1988). All values were corrected to a $14.0 \%$ moisture basis. Another strong type wheat flour was also obtained from Bicaci mill, Bihor county. This straight grade flour had a protein content of $11.7 \%$ (Nx57), ash content of $0.62 \%$, starch damage of 30 Farrand units (9.0 AACC units), and Farinograph absorption of $60.2 \%$. This wheat flours are too strong to develop at normal Farinograph speed (64 rpm). At $94 \mathrm{rpm}$,

Farinograph dough development time was $9.0 \mathrm{~min}$ with a stability of $17.5 \mathrm{~min}$.

\section{Baking}

The Environmental Protection Baking Laboratory develop short process for measurement of bread quality, was modified to suit conditions for frozen dough. Dough ingredients (basis percent flour weight) included $700 \mathrm{~g}(100 \%)$ flour (14\% moisture basis), fresh compressed yeast (5\%), salt (2.4\%), sugar (4.0\%), shortening (4.0\%), ascorbic acid (150 ppm), SSL ( $0.375 \%)$, enzymatic extract ( $0.6 \%$, containing alpha-amylase, oxidant free) and optimum baking absorption as assessed by hand feel after mixing and during panning. The ingredients were mixed in a small mixer with a cold water jacketed bowl at $130 \mathrm{rpm}$ to $10 \%$ past peak consistency. Final dough temperature was $18-20^{\circ} \mathrm{C}$. The bulk dough was immediately divided by hand (about $2 \mathrm{~min}$ ) into seven equal pieces, each representing $100 \mathrm{~g}$ flour. Each dough piece was then punched lightly seven times, rounded by hand, sheeted (three passes at 8.7, 4.8, and 3.2 $\mathrm{mm}$ ), and molded on the laminar molder. One dough piece was panned immediately, proofed and baked as a check for yeast viability. The remaining six dough pieces were placed into a $50 \mathrm{mc}$. low-temperature freezer equipped with a fan for air circulation at $-35^{\circ} \mathrm{C}$ for $2-3 \mathrm{~h}$ and then placed in a plastic bag and stored $\mathrm{f}$ at $-20^{\circ} \mathrm{C}$. Under these conditions, dough attained a core temperature of $0^{\circ} \mathrm{C}$ in less than $60 \mathrm{~min}$. Frozen dough were thawed and baked after 2 days and after 2, 8, 14, 20 and 26 weeks of frozen storage unless otherwise noted. Thawing was carried out at room temperature $\left(20-22^{\circ} \mathrm{C}\right)$ on a bench under a plastic sheet until core temperature reached $18^{\circ} \mathrm{C}(4-5 \mathrm{~h})$. Panning was carried out about $1 \mathrm{~h}$ into the thawing process when dough were sufficiently pliable. Proofing was carried out at $37.5^{\circ} \mathrm{C}$ and $83 \%$ relative humidity. Proof times for each frozen storage period for all treatments were determined by the time required for a thawed dough prepared from a control flour stored for the same time period to attain a proof height of $110 \mathrm{~mm}$ using standard formulation and processing conditions. After proofing, dough pieces 
were baked at $204^{\circ} \mathrm{C}$ for $25 \mathrm{~min}$. Baked loaf weights were recorded as soon as they were removed from the oven. After cooling (30-60 min), loaf volume was determined by rapeseed displacement. The loaves were scored the following day for external characteristics (loaf appearance), grain texture, crumb color and overall score.

\section{Experimental design}

To determine the effects of treatments (ingredient or processing conditions) on frozen dough quality during storage, bulk dough (seven dough pieces per dough used for fresh control plus six storage times) for each treatment level were prepared on the same day and repeated on two additional days. Control dough prepared using standard conditions (see above) were also included. These were used to determine proof times after each frozen storage period and to monitor the effects of unknown changes in laboratory conditions upon quality characteristics over the time during which the experiments were conducted. Experiments were treated statistically as blocked factorial designs and results were analyzed by analysis of variance (ANOVA). Statistically significant differences $(\mathrm{P}<0.05)$ between different treatment levels or storage times were determined by Duncan's multiple range test. Over the time period ( 8 months) during which experiments were conducted, coefficients of variability for loaf volume and bread score for control dough at the six storage times averaged 5.6 and $11.0 \%$, respectively.

Treatments included baking absorption level, mixing energy input, mixer type, fermentation and intermediate proof times, presence or absence of oxidant, SSL and DATEM, partial freeze-thaw cycles and addition (30\%) of an extra strong flour. Details are given in the next section.

\section{RESULTS AND DISCUSSION}

Preliminary studies showed that a dough (100 g flour basis) with a fresh yeast level of $5 \%$ proofed to a height of $110 \mathrm{~cm}$ gave optimum results. Proof times to attain the required proof height were very sensitive to frozen storage time for all treatments $(P<0.001)$. Using standard ingredient levels and processing conditions, proof time increased from an average of $58.2 \mathrm{~min}$ following 2 days of frozen storage to $100.2 \mathrm{~min}$ after 26 weeks (average of 15 results). The latter values would be considered as too long by industry. Most treatments also had significant effects upon proofing requirements. Longer fermentation time prior to freezing $(2-3 \mathrm{~h})$ and removal of oxidant showed the most dramatic effects while for other treatments, effects were small in comparison to frozen storage time. The large impact of longer fermentation time on proofing requirements for frozen dough has been associated with decreased yeast tolerance to freezing and frozen storage (Baguena et al., 1991). Increased proofing requirements associated with removal of oxidant are most likely due to reduced dough gas retention capacity related to insufficient oxidation of the gluten proteins (Bloksma and Bushuk, 1988).

All of the treatments selected had significant effects upon the baking quality of the strong wheat flour. In general, these effects were more pronounced with extended storage time, consistent with previous studies. The effects of these treatments on bread quality are discussed individually below.

\section{Baking absorption level}

The use of lower baking absorption for frozen dough is well documented (Davis, 1981), although systematic studies of absorption effects have not been previously published. The effects of varying baking absorption (54-69\%) upon frozen dough quality during storage are shown in Fig. 1. For the strong wheat flour, the optimum absorption based upon dough handling properties was $60 \%$, a value $7-8 \%$ lower than the corresponding value for fresh Romanian short process bread dough.
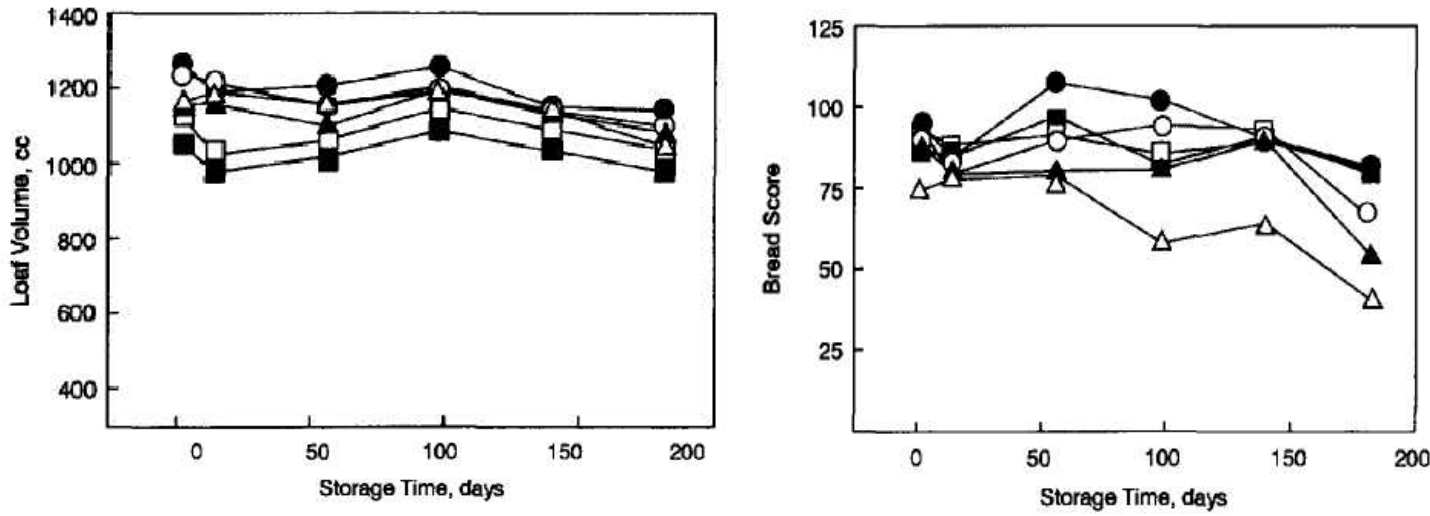

Fig. 1. Effects of baking absorption on loaf volume and bread score during prolonged storage (-. 54\%; Q, $57 \%$; . 60\%; O, 63\%; A, 66\%; A, 69\%). Root mean square error (RMSE) for volume $=83 \mathrm{~cm}^{3}$ and for score $=8.5$ units for each data point, $\mathrm{n}=3$.

At lower absorption levels, reduced $(P<0.05)$ loaf volumes were obtained. These lower volumes are probably related to the stiffer dough which lack sufficient extensibility to maintain high rates of expansion during proofing and oven rise. At higher absorption levels, bread scores were significantly lower than optimum values with the effect being most pronounced at extended storage times. The reduced bread scores were mainly attributable to inferior loaf appearance, as well as somewhat reduced grain texture and crumb color scores (data not shown). These effects may be related to "soft" dough properties associated with higher absorption which impart inferior handling and machining 
properties and lack the ability to maintain the "bold" shape during the oven rise required of good quality bread. At extended storage times, the much lower bread scores may also be caused by weakened dough properties associated with disruption of the gluten protein matrix. The higher absorption levels may accelerate this process due to excess "free" water.

\section{Mixing energy input and mixer type}

Figure 2 shows the effect of varying mixing energy input on a small pin mixer (130 rpm) from $50 \%$ under peak (UP) to $160 \%$ past peak (PP). A significant decrease in loaf volume and bread score occurred when dough was undermixed prior to freezing, consistent with fresh bread dough studies (Tipples and Kilborn, 1974). This effect became more pronounced with increasing frozen dough storage time. Changes among dough mixed to various energy inputs past peak were less evident. Loaf volume and bread score were slightly superior $(\mathrm{P}<0.05)$ at 20 and $40 \%$ past peak relative to values obtained at 10 and $160 \%$ past peak. Significant decreases in bread score also occurred at extended storage time, presumably related to weakened dough properties as discussed above. Strong wheat flours normally show optimum performance when mixed to about $10 \%$ past peak (Preston et al, 1982). With frozen dough, our results suggest that longer mixing (20-40\% past peak) may be desirable.

When dough were mixed to $10 \%$ past peak on different mixers, no significant difference in bread score was detected. Loaf volumes were, however, slightly $(, \mathrm{P}<0.05)$ higher with the spiral mixer. This difference may be related to mixing action.

\section{Fermentation and intermediate proof times}

Fermentation time after mixing was varied from 0 to $3 \mathrm{~h}$ at room temperature $\left(20 \sim 22^{\circ} \mathrm{C}\right)$ prior to freezing. As shown in Fig. 3, both loaf volume and bread score decreased rapidly after 8 weeks of storage when dough were fermented for 2 or $3 \mathrm{~h}$ prior to freezing. With shorter fermentation times $(0-1 \mathrm{~h})$, decreases in loaf volume and bread score during storage were much less evident. No problems were encountered in proofing these dough to the required height.
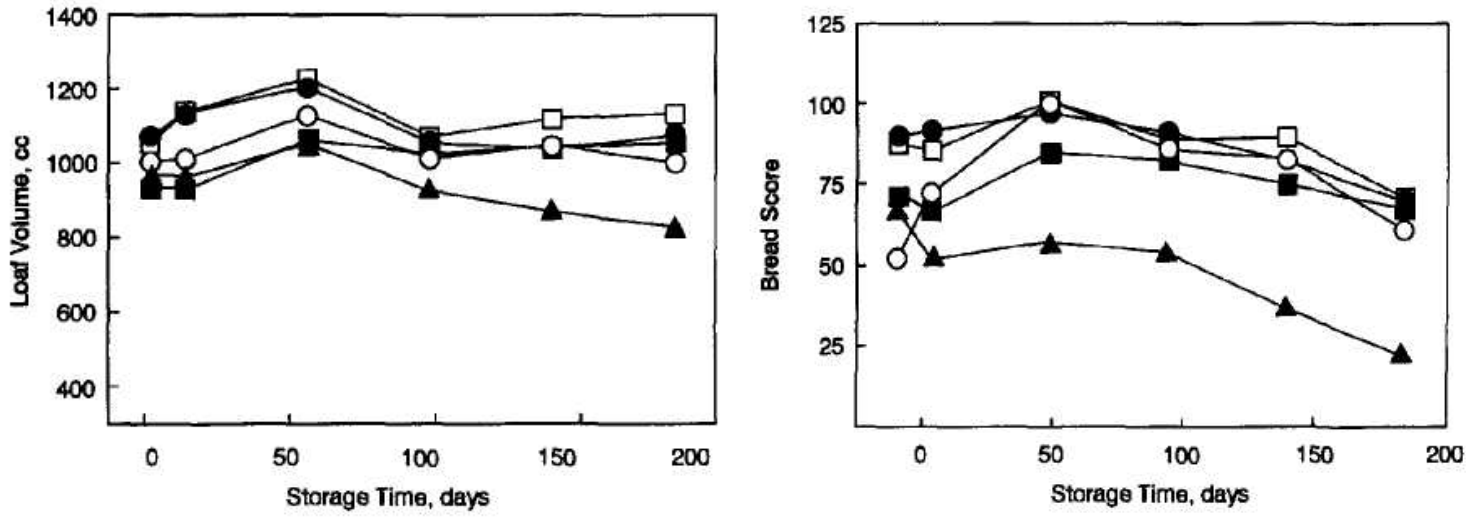

Fig. 2. Effects of mixing energy input in a small pin mixer on loaf volume and bread score during prolonged storage ( $\mathbf{(}$. $16 \mathrm{O}$ PP; Q, 4O PP; $\bullet 20$ PP; O, 1 O PP; A, 5 O UP; PP, past peak; UP, under peak). RMSE for volume $=73 \mathrm{~cm}^{3}$ and for score $=8.8$ units.

Short intermediate proof times are also normally recommended for frozen dough production. When intermediate proof times (after mixing and between dividing/rounding and moulding) were varied between 2 and $20 \mathrm{~min}$, small but significant differences in quality were evident. Loaf volume and bread score were somewhat lower $(\mathrm{P}<0.05)$ at the two shorter intermediate proof times including the 2 min treatment (2\&2) normally used for the baking procedure (Fig. 4). A significant drop in bread score was also evident at the longest storage time (26 weeks) for all intermediate proof times. These data indicate that longer intermediate proof times (10-15 min) can have a positive influence upon frozen dough bread quality. This may reflect the need for dough relaxation prior to further dough handling shown for fresh short process bread. In commercial practice, the first intermediate proof time (between mixing and dividing) varies within a batch of dough which can also influence the choice for this parameter.

\section{Oxidants and conditioners}

Figure 5 shows the effects of removing oxidant and dough conditioners on frozen dough bread quality. The removal of ascorbic acid resulted in large significant decreases in loaf volume and bread score over the entire storage period. Previous studies with frozen dough have shown similar results when levels of various oxidants were reduced or eliminated.

Removal of both conditioners plus ascorbic acid had a much greater effect $(\mathrm{P}<0.05)$ than removal of oxidant alone. Both of these conditioners have been shown to be effective improvers for frozen dough (Inoue et al., 1995), presumably by acting as dough strengthening agents which increase dough stability (Wolt and D'Appolonia, 1984). Removal of either conditioner did not have a significant effect upon 
bread quality, indicating that these conditioners appear to be equally effective at the levels used. Differences in flours and/or surfactant levels used in the two studies may be responsible for the contrary conclusion.

\section{Partial freeze-thaw cycles}

Previous studies have shown that freeze-thaw cycles, where dough appear to have been completely thawed, have strong detrimental effects upon frozen dough bread quality (Inoue and Bushuk, 1991). In addition to loss of yeast viability, assessment of the proofing dough by electron microscopy (Berglund et al., 1992) and Theological methods (Autio and Sinda, 1992) suggested that the loss of quality could be attributed to a weakening of the gluten protein structure, with the effects being most pronounced at longer storage times. When dough were thawed for $1 \mathrm{~h}$ at room temperature prior to refreezing, bread volumes showed significant decreases as the number of cycles was increased.
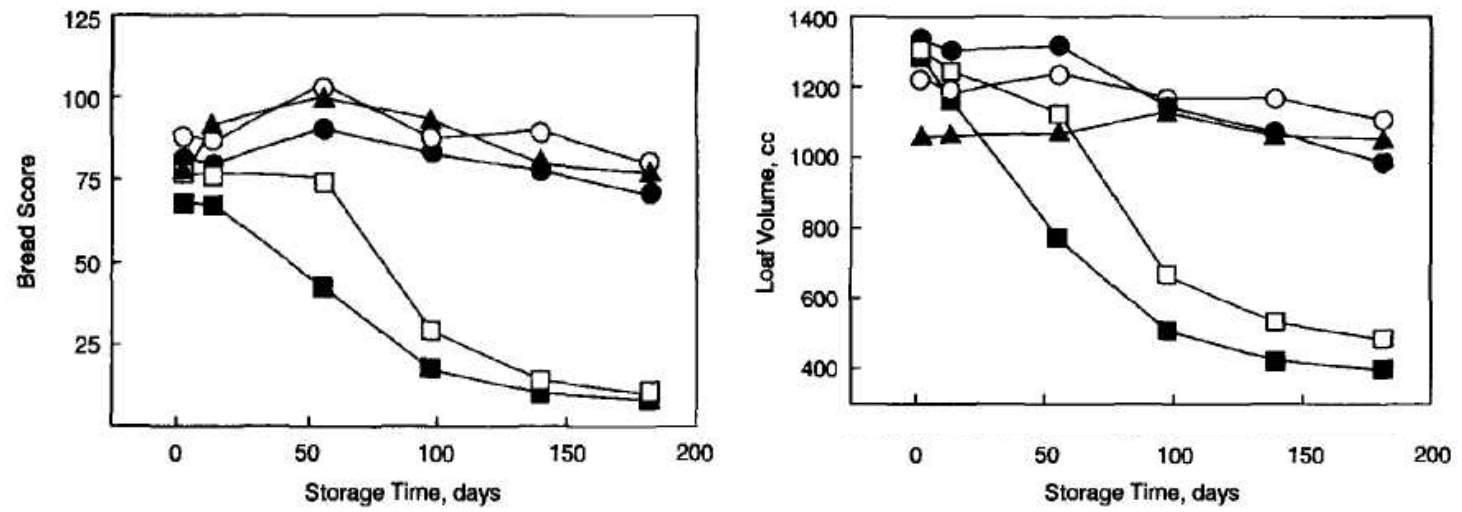

Fig. 3. Effects of fermentation time at room temperature on loaf volume and bread score during prolonged storage $(\boldsymbol{\varpi}, 3.0 \mathrm{~h}$; Q, $2.0 \mathrm{~h}$; «. $1.0 \mathrm{~h} ; \mathrm{O}, 0.5 \mathrm{~h} ; \mathrm{A}, 0.0 \mathrm{~h})$. RMSE for volume $=65 \mathrm{~cm}^{3}$ and for score $=7.0$ units for each data point, $\mathrm{n}=3$.
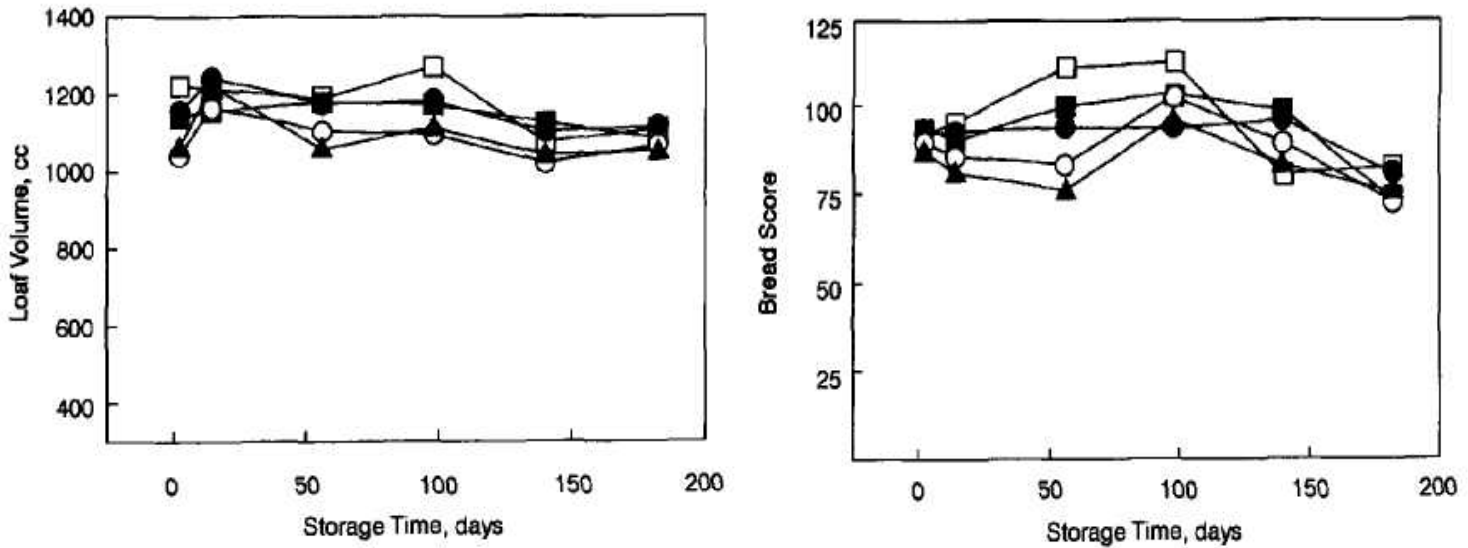

Fig. 4. Effects of intermediate proof times (after mixing and between dividing/rounding and moulding) on loaf volume and bread score during prolonged storage ( $\mathbf{\square}, 20 \& 20 \mathrm{~min}$; Q. 15\&15min; •. 10\&10 min; O, 5\&5 min; A, $2 \& 2 \mathrm{~min})$. RMSE for volume $=65 \mathrm{~cm}^{3}$ and for score $=10.5$ units for each data point, $\mathrm{n}=3$.

In the present study, frozen dough were subjected to partial simulated freeze-thaw cycles by placing dough on the bench at room temperature for $1 \mathrm{~h}$, then putting them back in the freezer. Only the surface of the dough thawed and temperature remained near the freezing point. The first cycle was started 1 week after initial freezing and then repeated at 1 week intervals. Dough subjected to zero, one, two and three freeze-thaw cycles were assessed. Storage times were 2 days from initial freezing, prior to any freeze thaw, and 4, 8, 10, 16 and 20 weeks after initial freezing. No significant differences were evident in bread score among freeze-thaw treatments (Fig. 6). Loaf volumes were slightly higher $(\mathrm{P}<0.05)$ with two or three partial freeze-thaw cycles relative to zero or one cycles. Bread score, but not loaf volume, showed significant decreases during storage with and without freeze-thaw cycles.

The reasons for the contrast between our results, indicating that partial freeze cycles had little influence upon quality, and those showing a significant negative influence, are not easily explained. However, differences in formulation may offer one possible explanation. In our studies, a full formula including dough strengthening conditioners was used a leaner formula where lack of conditioners may have reduced the stability of the dough. 


\section{Stronger wheat flour}

Studies on the effect of flour dough strength properties on the performance of frozen dough have been contradictory. Wolt and D'Appolonia (1984) found that the rheological properties of several commercial patent and laboratory milled flours were not related to frozen dough baking performance.
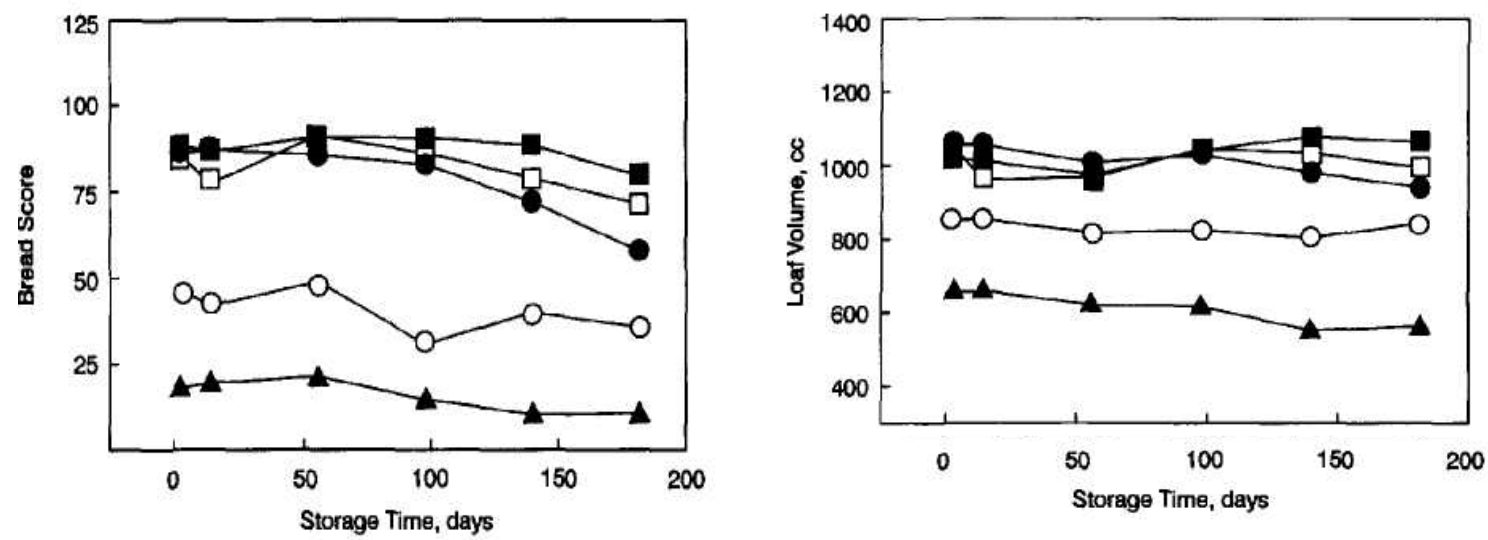

Fig. 5. Effects of removing oxidant and dough conditioners on loaf volume and bread score during prolonged storage ( $\square$, full formula; $\square$, no SSL; \#, no DATEM; O, no ascorbic acid; A, no SSL, DATEM and ascorbic acid). RMSE for volume $=47 \mathrm{~cm}^{3}$ and for score $=6.1$ units for each data point, $n=3$.

In contrast, Inoue and Bushuk (1992) found that a very strong flour gave superior performance compared to a wheat flour with medium-strong dough properties. They presented evidence, based upon modified extensigraph curves obtained from thawed frozen dough, that stronger flours are better able to counteract the loss of dough strength on freezing, during frozen storage and upon thawing than weaker flours. However, $100 \%$ strong wheat flours cannot be easily utilized in industrial plants due to very long mixing requirements. The large bar mixers normally used in frozen dough plants cannot easily handle levels of above about $30 \%$ strong wheat flour when mixed with wheat flour.
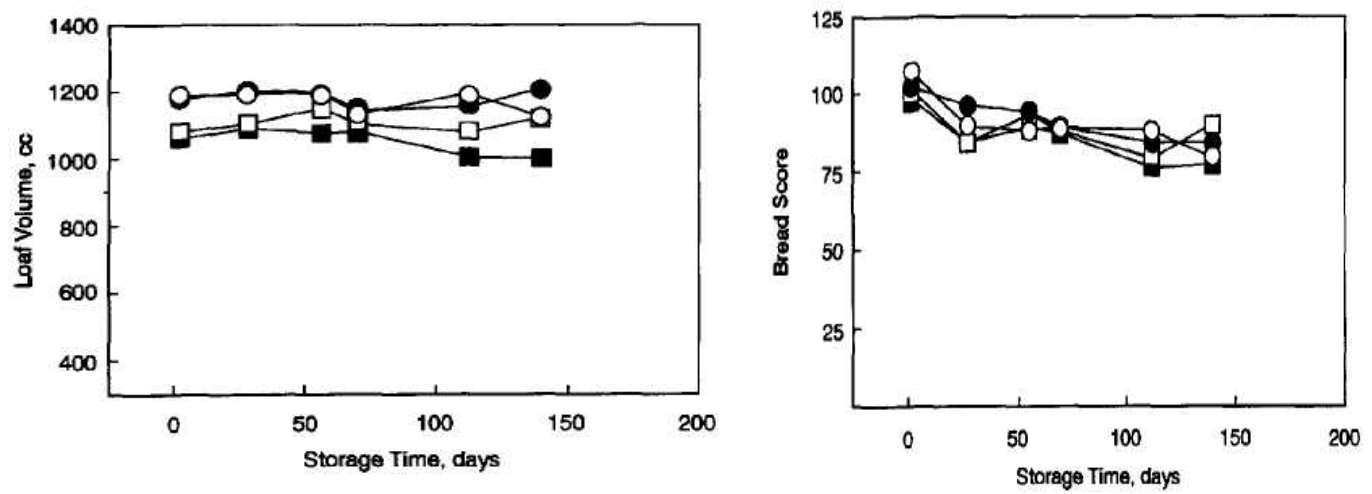

Fig. 6. Effects of partial freeze-thaw cycles ( $1 \mathrm{~h}$ at room temperature) on loaf volume and bread score during prolonged storage ( $\mathbf{m}$. none; Q, one; $\bullet$. two; O, three). RMSE for volume $=72 \mathrm{~cm}^{3}$ and for score $=7.2$ units for each data point
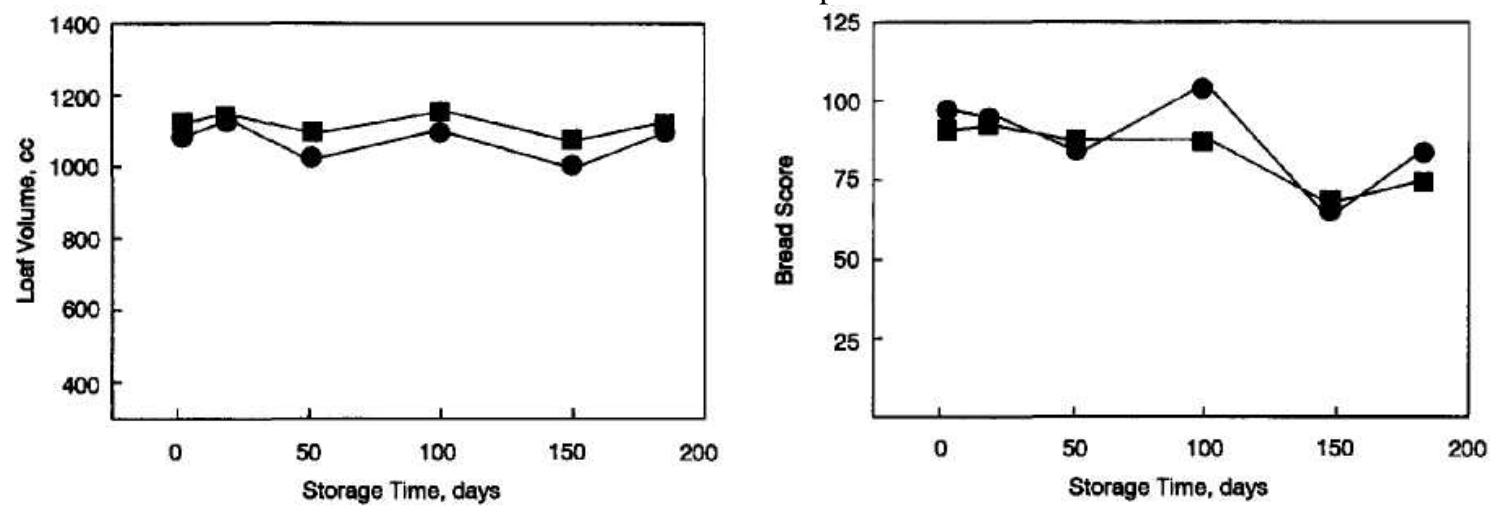

Fig. 7. Comparison between effects of $100 \%$ medium - strong wheat flour ( $\mathbf{a})$ and strong wheat flour strengthened by the addition of $30 \%$ strong wheatt flour on loaf volume and bread score during prolonged storage. RMSE for volume $=42 \mathrm{~cm}^{3}$ and for score $=5.5$ units for each data point, $n=3$. 
Figure 7 shows the effect on frozen dough bread quality of a $30 \%$ blend of strong with medium - strong wheat flour relative to $100 \%$ medium strong. wheat flour Mixing energy requirements for the $30 \% \mathrm{blend}(22.6 \mathrm{wh} / \mathrm{kg})$ increased by $33 \%$ compared to the $100 \%$ medium - strong wheat flour $(17.1 \mathrm{wh} / \mathrm{kg})$ while peak mixing time increased from 7.2 to 9.4 min (average of three determinations) on the small pin mixer.

No significant differences were evident in loaf volume or bread score between the two flours over the frozen dough storage period. The reasons for the lack of response to dough strength compared to the strong positive effect obtained by Inoue and Bushuk (1992) may be partly related to the different levels of strong wheat flour used (100 versus 30\%). However, the lack of dough strengthening conditioners in is probably the major factor. In the absence of SSL and/or DATEM, the weaker dough strength of the $100 \%$ medium - strong wheat flour may be less effective than the stronger blended flour in counteracting the dough weakening associated with freezing, frozen storage and thawing as discussed above. Data from Fig. 5, as well shown the effects of SSL and/or DATEM on frozen dough quality, support this conclusion.

The blended flour was also subjected to the same treatments as the $100 \%$ strong wheat flour.

\section{CONCLUSIONS}

In general, the effects of the treatments on the bread quality of the former were very similar compared to the effects upon the latter. However, the stronger blended flour showed superior performance in a number of situations where suboptimum conditions were tested including higher absorption levels, undermixing and removal of ascorbic acid and ascorbic acid and dough conditioners.

These results suggest that stronger flours may impart superior tolerance where processing and ingredients are not optimized.

\section{REFERENCES}

1. Autio, K. and Sinda, E. (1992). Frozen doughs. Rheological changes and yeast viability. Cereal Chem. 69, 409-413.

2. BAGUENA, R., SORIANO, M. D., MARTINEZ-ANAYA, M. A. and BENEDITO DE BARBER, C. (1991). Viability and performance of pure yeast strains in frozen wheat dough. I. Food Sci. 56, 1690-1698.

3. Berglund, P. T. And Shelton, D. R. (1993). Effect of frozen storage duration on firming properties of breads baked from frozen doughs. Cereal Foods World 38, 89-93.

4. Bloksma, A. H. and Bushuk, W. (1988). Rheology and chemistry of dough. In Wheat Chemistry and Technology, Vol. II. ed. Y. Pomeranz, AACC, St Paul, MN, pp. 131-217.

5. Davis, E. W. (1981). Shelf-life studies on frozen doughs. Bakers Dig. 55(3), 1214.

6. Dubois, D. K. and Blockcolsky, D. (1986a). Frozen bread dough, effect of additives. Am. Inst. Baking Res. Dept. Tech. Bull. 8(April), 17.

7. Gelinas, P., Lagimoniere, M. and Dubord, C. (1993). Baker's yeast sampling and frozen dough stability. Cereal Chem. 70, $219-225$.

8. Himmelstein, A. (1984). Enzyme treatment of flour. Will it help frozen and retarded doughs? Bakers Dig. 58(5), 8-12.

9. Hosomi, K., Nishio, K. and Matsumoto, H. (1992). Studies on frozen dough baking. I. Effects of egg yolk and sugar ester. Cereal Chem. 69, 89-92.

10. Hsu, K. H., Hoseney, R. C. and Seib, P. A. (1979). Frozen dough. I. Factors affecting stability of yeasted doughs. Cereal Chem. $56,419423$.

11. Inoue, Y. and Bushuk, W. (1992). Studies on frozen doughs. II. Flour quality requirements for bread production from frozen dough. Cereal Chem. 69, 423 - 128.

12. Inoue, Y., Sapirstein, H. D., Takayanagi, S.,Bushuk, W.(1994). Studies on frozen doughs. III. Some factors involved in dough weakening during frozen storage and thaw-freeze cycles. Cereal Chem. 71, 118- 121.

13. Inoue, Y., Sapirstein, H. D.,Bushuk, W. (1995). Studies on frozen doughs. IV. Effect of shortening systems on baking and rheological properties. Cereal Chem. 72, 221-224.

14. Kilborn, R. H.,Tipples, K. H. (1979). The effect of oxidation and intermediate proof on work requirements for optimum shortprocess bread. Cereal Chem. 56, 407-412.

15. Lorenz, K. (1974). Frozen dough. Present trend and future outlook. Bakers Dig. 48(2), 14-22, 30.

16. Cary, Nc. Tipples, K. H., Kilborn, R. H. (1974). Dough development for shorter breadmaking processes. Bakers Dig. 48(5), 34-39.

17. Takasaki, S., Karasawa, K. (1992). Effect of storage period on survival of freeze tolerant yeast and on the rheological properties of frozen dough. Nippon Shokuhin Kogyo Gakkaishi 39, 813-820.

18. Varriano-Marston, E., Hsu, K. H., Mahdi, J. (1980). Rheological and structural changes in frozen dough. Bakers Dig. 54(1), 3234,41 .

19. Wang, Z. J., Ponte Jr, J. G. (1994). Improving frozen dough qualities with the addition of vital wheat gluten. Cereal Foods World 39, 500-503.

20. Wolt, M. J. ,D'appolonia, B. L. (1984). Factors involved in the stability of frozen dough. II. The effects of yeast type, flour type, and dough additives on frozen-dough stability. Cereal Chem. 61, 213-221. 